\title{
Biological Control of the Nematode Infective larvae of Trichostrongylidae Family With Filamentous Fungi
}

\author{
Majid Zarrin ${ }^{1,2} ;$ Mahmoud Rahdar $^{3,4,} ;$ Abbas Gholamian $^{5}$ \\ ${ }^{1}$ Health research Institute, Infectious and Tropical Diseases Research Center, Jundishapur University of Medical Sciences, Ahvaz, IR Iran \\ ${ }^{2}$ Department of Medical Mycology, School of Medicine, Ahvaz Jundishapur University of Medical Sciences, Ahvaz, IR Iran \\ ${ }^{3}$ Department of Medical Parasitology, School of Medicine, Ahvaz Jundishapur University of Medical Sciences, Ahvaz, IR Iran \\ ${ }^{4}$ Cellular and Molecular Researches Center, Ahvaz Jundishapur University of Medical Sciences, Ahvaz, IR Iran \\ 5 Laboratory Department, Khuzestan Veterinary Office, Ahvaz, IR Iran \\ *Corresponding author: Mahmoud Rahdar, Department of Medical Parasitology, School of Medicine, Ahvaz Jundishapur University of Medical Sciences, Ahvaz, IR Iran \\ Tel:+98-6133388401, Fax: +98-6133332036, E-mail: mrahdar2002@yahoo.com
}

Received: January 15, 2014; Revised: May 12, 2014; Accepted: September 15, 2014

\begin{abstract}
Background: Biological control of parasitic nematodes by microorganisms is a promising approach to control such parasites. Microorganisms such as fungi, viruses and bacteria are recognized as biocontrol agents of nematodes.

Objectives: The current study mainly aimed to evaluate the in vitro Potential of various saprophyte soil-fungi in reducing the infective larvae stage of parasitic nematode Trichostrongylidae family.

Materials and Methods: Sheep feces were employed to provide the required third stage larvae source for the experiments. The nematode infective larvae of Trichostrongylidae family including three species of Ostertagia circumcincta, Marshalgia marshali and Heamonchos contortus were collected by Berman apparatus. Fifteen isolates of filamentous fungi were tested in the current study. One milliliter suspension containing 200 third stage larvae of Trichostrongylidae family was separately added to the fungal cultures in $2 \%$ water-agar medium Petridishes. Every day the live larvae were counted with light microscope (10X) and the number of captured larvae was recorded on different days.

Results: Significant differences were observed in the results of co-culture of nematodes larva and fungi after seven days. The most effective fungi against the nematodes larvae were Cladosporium sp., Trichoderma sp., Fusarium equisetti, after seven days of incubation.

Conclusions: The studies on fungi could be applied as suitable tools in biocontrol of nematode infections. However, additional surveys are required to select efficient with the ability to reduce the nematode larvae in the environment.
\end{abstract}

Keywords: Biological Control Agents; Filamentous Fungi; Nematode Infections

\section{Background}

Biological control by microorganisms is a promising approach to control parasitic nematodes. Microorganisms such as fungi, viruses and bacteria are recognized as biocontrol agents (1). Nematodes are a large group of parasites which cause serious economic and hygienic problems in plants, animals and humans. They play an important role in reducing plant and animal products (2). Several programs are developed to minimize the unfavorable effects of gastrointestinal parasites (3). Some of the programs attempted to reduce the infective larvae with antihelminthic compounds to reduce nematode infections in adult animals. Even though using the antihelminthic compounds are the major tools to treat gastrointestinal parasites, there are limitations regarding their usage in drug residual in animal products such as milk and meat (4). These compounds can be also toxic for non-target organisms (5) and helminthes because of resistance to the antihelminthics (6).

Developing alternative methods instead of antihelminthics compounds against ruminant nemathodes is a serious need. Biological control seems to be a safe and efficient idea to decrease the population of infective nematodes larvae in gastrointestinal tract and pastures. Nematophagous fungi can capture and digest nematodes by producing hyphae around them. After 24 hours, hyphae differentiation happens and different structures are generated for trapping. Gray described six main forms of trapping (7). De Souza Maia Filho et al. (8) evaluated ovicidal effect on Toxacara canis ova by using several species of fungi including Acremonium, Aspergillus, Bipolaris, Fusarium, Gliocladium, Mucor and Trichoderma isolated from local soil. The results showed that Trichoderma, Fusarium solani complex and Acremonium have more ovicidal effect on T. canis ova (8). Agriculture nematodes were controlled by nematocidal activity of Fusarium and Paecilomyces species isolated in India.

Mishra and Dwivedi indicated a reduction in the number of nematode farms such as root-knot Meloidogyne incognita and M. javanica, and reniform Rotylenchulus reniformiss using Fusarium and Paecilomyces isolates (9). Aybeke et al. showed that Aspergillus alliaceus can be used as a potential biological controlling agent on root parasitic weed

Copyright (c) 2015, Ahvaz Jundishapur University of Medical Sciences. This is an open-access article distributed under the terms of the Creative Commons Attribution-NonCommercial 4.0 International License (http://creativecommons.org/licenses/by-nc/4.0/) which permits copy and redistribute the material just in noncommercial usages, provided the original work is properly cited. 
orobanche population (10). Various types of fungi, mostly belonging to Ascomycota, demonstrate antagonistic effects on eggs and parasitic nematodes in animal or human. The secretion of nematode-antagonistic compounds in $F$. equiseti isolated from soybean cyst is recognized (11). The species of Aspergillus usually produce various secondary metabolites. These metabolites can influence the creation of nematicidal agents and promote the nematocidal activity of some bacteria in plant (12). Siddiqui et al. showed that Trichoderma harzianum enhanced the production of nematicidal compounds in laboratory and developed biocontrol of Meloidogyne javanica with Pseudomonas fluorescens in tomato (13).

\section{Objectives}

The current study mainly aimed to evaluate the in vitro activities of various saprophyte soil-fungi to reduce the infective larvae stage of parasitic nematode Trichostrongylidae family.

\section{Materials and Methods}

\subsection{Preparation of Trichostrongylidae Family Larval Stage}

Sheep feces were employed to provide the required larvae source for the experiments. The contamination of feces to infective parasite was confirmed by microscopic examination. Two-hundred grams of feces from each sheep was incubated in room temperature for 10 days. The third stage infective larvae of Trichostrongylidae family containing Ostertagia circumcincta, Marshalgia marshali and Haemonchos contortus, were collected by Berman apparatus. To obtain larvae without fecal fungi and bacteria, they were washed 10 times in normal saline by centrifugation for two minutes at $500 \mathrm{rpm}$. The larvae were kept at $4^{\circ} \mathrm{C}$ in a solution including antibiotics penicillin-streptomycin (Sigma, Germany) and amphotericin B (fungizone/Brstol-Myers Squibb, Paris) to prevent bacteria and fungi growth.

\subsection{Preparation of Fungi}

Fifteen isolates of filamentous fungi including Penicillium sp., A. flavus, Cladosporium sp., Trichoderma sp., F. equisetti, Paecilomyces sp., A. niger, Fusarium sp., Acremonium sp., Alternaria sp., Derecselera sp., Trichotecium sp. and Curvularia sp. were tested in the current study. The collected fungi were identified by a mycologist using special media and according to colony morphology characters and light microscope. The tested fungi were collected from environment. The fungi were cultured on Sabouraud dextrose agar (Merck, Germany) at room temperature for 3 days. The grown fungi were transferred on potato dextrose agar (PDA) (Merck, Germany) for three days at room temperature. After grow of fungi on PDA, $7 \mathrm{~mm}$ diameter mycelium culture discs were cut and transferred to plates containing $2 \%$ water-agar medium with 1\% gentamycin (Sigma, Germany). The Petridishes were kept at room temperature for three days.

\subsection{Co-culture of Fungi and Larvae}

The larvae were washed 10 times with normal saline to remove antibiotics. On the 4 th day, $1 \mathrm{~mL}$ of larvae culture suspension containing 200 third stage nematode larvae from Trichostrongylidae family L3 was separately added to the fungal cultures in $2 \%$ water-agar medium Petri-dishes. Every day the live larvae were counted by light microscope $(10 X)$ and the number of captured larvae was recorded in different days. The experiments were repeated three times (1). The control groups were use in each isolated fungi to compare data with the test groups.

\subsection{Statistical Analysis}

The data were analyzed by Chi-square test ( $\alpha=5 \%$ confidence index) and descriptive analysis by SPSS software version 16 (SPSS, Inc, Chicago, IL, USA). The level of significance was considered as $\mathrm{P}<0.05$.

\section{Results}

The Table 1 shows the results of 15 isolates from 13 different tested fungi in this study. These results indicated the highest level of efficiency among the isolates after seven days coculture of nematodes larvae and fungi. The most effective fungi against the nematodes larvae were Cladosporium sp., Trichoderma sp., and F. equisetti after seven days of incubation. Derecselera sp., Trichothecium sp. and Curvularia sp. had no significant effect on the reduction of live larvae population, compared with the control group, after seven days incubation $(\mathrm{P}>0.05)$. Penicillium sp., A. flavus, Paecilomyces sp., A. niger, Acremonium sp., Alternaria sp. and Fusarium sp. reduced significantly the live larvae after seven days incubation $(\mathrm{P}<0.01)$. The killed larvae were introduced by being immobilized, elongation and appearance of several vacouele in body and cuticule of the larvae. The live larvae have sinuosity movement in the culture media. Figure 1 shows the trapped larvae by fungus.

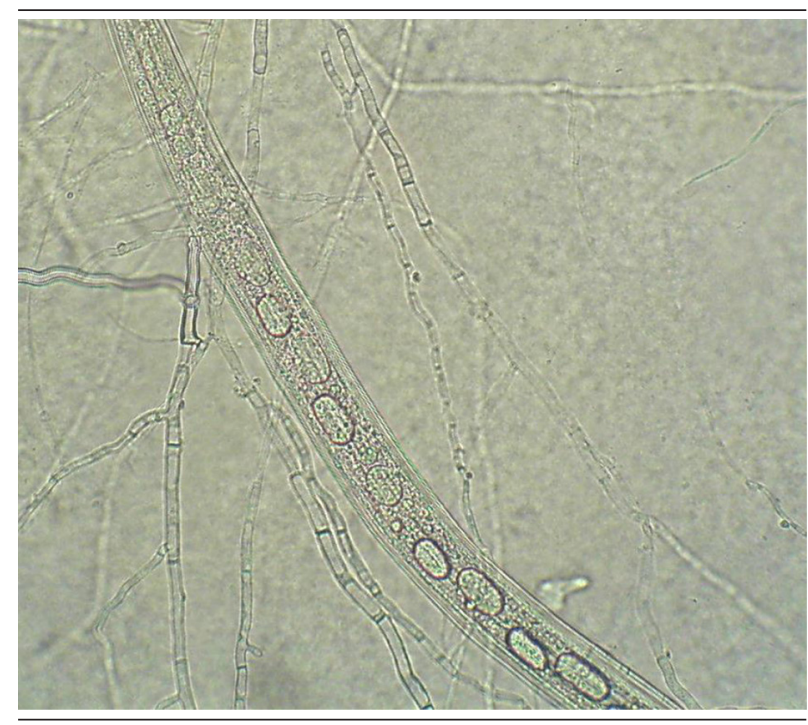

Figure 1. The Trapped Nematode Larvae by Mycelium of Fungus 
Zarrin M et al.

Table 1. The Nematophagus Effects of Studied Fungi on Third Stage Larvae Population

\begin{tabular}{lcccc}
\hline Fungi & $\begin{array}{c}\text { Decrease of Larvae Population } \\
\text { (\%) in the Test Group }\end{array}$ & $\begin{array}{c}\text { The Percentage of Live Larvae } \\
\text { in the Test Groups }\end{array}$ & $\begin{array}{c}\text { Decrease of Larvae Population } \\
\text { (\%) in the Control Group }\end{array}$ & $\begin{array}{c}\text { P Value } \\
\text { Penicillium sp. }\end{array}$ \\
\hline Aspergillus flavus & 95 & 5 & 63.5 & $<0.01$ \\
\hline Cladosporium sp. & 96.7 & 3.3 & 63.5 & $<0.01$ \\
\hline Trichoderma sp. & 98.8 & 1.2 & 63.5 & $<0.01$ \\
\hline Trichoderma sp. & 97.8 & 2.2 & 63.5 & $<0.01$ \\
\hline Trichoderma sp. & 98.5 & 1.5 & 63.5 & $<0.01$ \\
\hline Fusarium equisetti & 97.8 & 2.2 & 63.5 & $<0.01$ \\
\hline Paecilomyces sp. & 95.5 & 4.5 & 63.5 & $<0.01$ \\
\hline Aspergillus niger & 91.5 & 9.5 & 63.5 & $<0.01$ \\
\hline Fusarium sp. & 88.9 & 11.1 & 63.5 & $<0.01$ \\
\hline Acremonium sp. & 89.5 & 10.5 & 63.5 & $<0.01$ \\
\hline Alternaria sp. & 93 & 7 & 63.5 & $<0.01$ \\
\hline Derecselera sp. & 91.2 & 8.8 & 63.5 & $<0.01$ \\
\hline Trichothecium sp. & 69.3 & 30.7 & 63.5 & $>0.05$ \\
\hline Curvularia sp. & 51.25 & 48.75 & 63.5 & $>0.05$ \\
\hline
\end{tabular}

\section{Discussion}

Controlling nematodes in agriculture, livestock industries and human community is an important program in many countries. Currently, chemical agents and antinematode drugs are utilized to control and treat nematode diseases. Countries must spend large amount of money to control and eliminate nematodes. The resistance of nematodes against anti-nematode drugs has increased since many years ago. It seems that chemical control is not completely effective for this purpose. In recent years, biologic control of nematodes is dramatically considered by many investigators (14-16). Controlling nematodes by fungi is investigated in many countries (17). The current study results demonstrated that some saprophytic fungi spread in the environment can be effective in reducing the number of third stage larvae of Trichostrongylidae family. However the rate of removing is different depending on the fungal species and isolates.

There was a considerable decrease in Cladosporium sp., Trichoderma sp. and A. flavus culture. These results indicated great potential of using appropriate saprophyte fungi for biological control of Trichostrongylidae family larvae in sheep. Two factors including adaptability to the environment and ability to produce extracellular enzymes which contribute in the process of infection are the major characteristics of selecting potentially suitable fungus to be employed as an agent for biocontrol $(18,19)$. In the current research, three fungi Derecselera, Trichothecium, Curvularia species did not show nematophagous activity against Trichostrongylidae family larvae in sheep. To employ fungi isolates as biological control, identifying the factors affecting natural control of nematodes is necessary. The in vitro efficacy of predacious fungal isolates on parasitic nematodes of cattle, Cooperia punctata and Haemonchus placei has been indicated by a previous study (20). In addition, the in vivo biological control of parasites is shown in bovine by nematode-trapping fungi (21).

Other researchers reported the capability of $A$. robusta isolates in the biological control of nematode parasites in bovine gastrointestinal. It seems that D. flagrans has nematocidal activity; hence, it is used to control Ostertagia sp., Cooperia sp., Dictyocaulus sp. and H. contortus (2224). One of the predatory fungi that make tridimensional nets is Arthrobotrys genus. This fungus consists of one to three cells covered with adhesive material. In spite of the kind of trap, the entrapped nematode ineffectively struggle for relieve themselves (25). Free-living nematodes of Panagrellus sp. are used in many laboratories across the world. This nematode is used as bait for the isolation and predation experiments of nematophagous fungi. In trapping tests by Gomes et al. Panagrellus sp. showed high susceptibility to predation by the entire genus Monacrosporium isolates (26).

The larvae nematodes are reduced, particularly in young lambs. Also, Duddingtonia flagrans can be as potential tool for biological controlling of nematodes by nematodedestroying ability. The fungus creates sticky traps and seizes developing larval stages of parasitic nematodes in the feces of animals (27). After feeding the grazing sheep with the spores of $D$. flagrans, biological control has become an important tool in maintaining an appropriate system of sheep products. Regarding the time of infection, the fungus has various effects including decrease in the population of mature females, fecundity, and eggs parasitism (23). In conclusion, the studied fungal isolates 
could be applied as a suitable alternative to resolve the problems related to nematode infection. Compared with the chemical compounds, biological control agents need longer time and have lower ability to rapidly control of the nematodes infection. Combination of two methods for effective nematodes control program may be considered. In addition, more in vivo surveys are required to choose isolates which affect nematodes larvae in the environment.

\section{Authors' Contributions}

Abbas Gholamian: preparation and collection of third larvae stage of the sheep nematodes. Mahmoud Rahdar: culturing, counting and storage of the larvae, evaluation of co-culture and counting killing larvae in media and doing statistical tests. Majid Zarrin: identification of studied fungi and culturing.

\section{Funding/support}

This research project was financially supported by Infectious and Tropical Diseases Research Center, Ahvaz Jundishapur University of Medical Sciences (Grant no. 85106).

\section{References}

1. Gomes AP, Ramos ML, Vasconcellos RS, Jensen JR, Vieira-Bressan MC, Araujo JV. In vitro activity of Brazilian strains of the predatory fungi Arthrobotrys spp. on free-living nematodes and infective larvae of Haemonchus placei. Mem Inst Oswaldo Cruz 2000;95(6):873-6.

2. Ahman J, Johansson T, Olsson M, Punt PJ, van den Hondel CA Tunlid A. Improving the pathogenicity of a nematode-trapping fungus by genetic engineering of a subtilisin with nematotoxic activity. Appl Environ Microbiol. 2002;68(7):3408-15.

3. Buske R, Santurio JM, de Oliveira CV, Bianchini LA, da Silva JH, de la Rue ML. In vitro influence of temperature on the biological control activity of the fungus Duddingtonia flagrans against Haemonchus contortus in sheep. Parasitol Res. 2013;112(2):473-8.

4. Padilha T. Anthelmintic residues in meat and milk. In: Padilha T editor. Control of gastrointestinal nematodes in ruminants.. Coronel Pacheco: CNPGL-Embrapa; 1996. pp. 77-93.

5. Strong L, Wall R, Woolford A, Djeddour D. The effect of faecally excreted ivermectin and fenbendazole on the insect colonisation of cattle dung following the oral administration of sustainedrelease boluses. Vet Parasitol.1996;62(3-4):253-66.

6. Kaplan RM. Drug resistance in nematodes of veterinary importance: a status report. Trends Parasitol. 2004;20(10):477-81.

7. Gray NF. Fungi attacking vermiform nematodes. In: Poinar J, Jansson HB editors. Diseases of Nematodes, Vol. II.. CRC Press: Boca Raton; 1988.

8. De Souza Maia Filho F, Nunes Vieira J, Aires Berne ME, Stoll FE, Da Silva Nascente P, Potter L, et al. Fungal ovicidal activity on Toxocara canis eggs. Rev Iberoam Micol. 2013;30(4):226-30.

9. Mishra SD, Dwivedi BK. Identification of most suitable seed treat- ment based option for the management of key nematode pests of pulse crops. Curr Nematol. 2008;19:1-13.

10. Aybeke M, Sen B, Okten S. Aspergillus alliaceus, a new potential biological control of the root parasitic weed Orobanche. J Basic Microbiol. 2014;54 Suppl 1:S93-101.

11. Nitao JK, Meyer SL, Schmidt WF, Fettinger JC, Chitwood DJ. Nem atode-antagonistic trichothecenes from Fusarium equiseti. Chem Ecol. 2001;27(5):859-69.

12. Siddiqui IA, Shaukat SS. Trichoderma harzianum enhances the production of nematicidal compounds in vitro and improves biocontrol of Meloidogyne javanica by Pseudomonas fluorescens in tomato. Lett Appl Microbiol. 2004;38(2):169-75.

13. Siddiqui IA, Shaukat SS, Khan A. Differential impact of some Aspergillus species on Meloidogyne javanica biocontrol by Pseudomonas fluorescens strain CHAO. Lett Appl Microbiol. 2004;39(1):74-83.

14. Siddiqui ZA, Mahmood I. Biological control of plant parasitic nematodes by fungi: A review. Bioresour Technol. 1996; 58(3):229-39.

15. Waller PJ, Faedo M. The prospects for biological control of the free-living stages of nematode parasites of livestock. Int J Parasitol. 1996;26(8-9):915-25.

16. Dijksterhuis J, Veenhuis M, Harder W, Nordbring-Hertz B. Nematophagous fungi: physiological aspects and structure-function relationships. Adv Microb Physiol. 1994;36:111-43.

17. Larsen M. Biological control in a global perspective-a review with emphasis on Duddingtonia flagrans. FAO R(PAHD editor. Rome: FAO; 2002.

18. Barranco-Florido JE, Alatorre-Rosas R, Gutiérrez-Rojas M, Vinieg ra-González G, Saucedo-Castañeda G. Criteria for the selection of strains of entomopathogenic fungi Verticillium lecanii for solid state cultivation. Enzyme Microb Technol. 2002;30(7):910-5.

19. Olivares CM, Lopez-Llorca LV. Fungal egg-parasites of plantparasitic nematodes from Spanish soils. Rev Iberoam Micol. 2002;19(2):104-10.

20. Olivares-Bernabeu C, Lopez-Llorca LV. Biological Control In Vivo Nematode parasites Gastrointestinal cattle by Fungus Arthrobotrys robusta and Activity in Vitro isolates fungus Monacrosporium on Nematodes.: Magazine Iberoamericana mycology; 2002.

21. Araujo JV, Gomes APS, Guimaraes MP. Biological control of bovine gastrointestinal parasites in southeastern by the nematode-trapping fungus Arthrobotrys robusta.: Magazine Brazilian of Parasitology Veterinary; 1998.

22. Larsen M. Biological control of helminths. Int $J$ Parasitol. 1999;29(1):139-46.

23. Chandrawathani P, Jamnah O, Adnan M, Waller PJ, Larsen M, Gillespie AT. Field studies on the biological control of nematode parasites of sheep in the tropics, using the microfungus Duddingtonia flagrans. Vet Parasitol. 2004;120(3):177-87.

24. Waller PJ, Schwan O, Ljungstrom BL, Rydzik A, Yeates GW. Evaluation of biological control of sheep parasites using Duddingtonia flagrans under commercial farming conditions on the island of Gotland, Sweden. Vet Parasitol. 2004;126(3):299-315.

25. Barron GL. The nematode-destroying fungi.: Canadian Biological Publications Ltd.; 1977.

26. Gomes AP, Araujo JV, Ribeiro RC. Differential in vitro pathogenicity of predatory fungi of the genus Monacrosporium for phytonematodes, free-living nematodes and parasitic nematodes of cattle. Braz J Med Biol Res. 1999;32(1):79-83.

27. Fernandez AS, Larsen M, Nansen P, Gronvold J, Henriksen SA Bjorn $\mathrm{H}$, et al. The efficacy of two isolates of the nematode-trapping fungus Duddingtonia flagrans against Dictyocaulus viviparus larvae in faeces. Vet Parasitol. 1999;85(4):289-304. 